\title{
Inducible Resistance to Tetracycline in Staphylococcus aureus
}

\author{
By D. SOMPOLINSKY, TALYA KRAWITZ, Y. ZAIDENZAIG \\ AND NILI ABRAMOVA \\ Rapaport Laboratories for Microbiology, Bar Ilan University, Ramat Gan, and \\ Department of Bacteriology, Asaf Harofe Government Hospital, \\ University of Tel-Aviv Medical School, Zrifin, Israel
}

(Accepted for publication I5 May 1970)

\section{SUMMARY}

When staphylococci, resistant to $4 \mu \mathrm{g}$. tetracycline $/ \mathrm{ml}$., were grown in nutrient media at subinhibitory levels of the drug, phenotypical resistance increased until the cocci grew with $\mathrm{I} 60 \mu \mathrm{g}$. tetracycline $/ \mathrm{ml}$. Resistance increased most rapidly at the highest concentration of tetracycline which did not significantly inhibit growth. Increase in resistance was also obtained by pre-incubation with $\beta$-apo-5-oxy-tetracycline. Increase in resistance could be prevented by chloramphenicol and actinomycin D, but not by nalidixic acid. When a highly resistant culture was transferred to tetracycline-free medium, phenotypical resistance decreased gradually; after four transfers on nutrient agar it returned entirely to the original level.

\section{INTRODUCTION}

Williams (1967) has drawn attention to the resistance to mercury salts (Moore, 1960) of tetracycline-resistant strains of Staphylococcus aureus. Resistance to tetracycline was in general correlated with resistance to mercury; in mercury-sensitive strains, however, high-level resistance to tetracycline could be obtained by 'training', i.e. growth in peptone water containing $3 \mu \mathrm{g}$. antibiotic/ml.

\section{METHODS}

Bacterial strains. The strain studied, Staphylococcus aureus II I (Sompolinsky, Yiflah \& Aboud, I968), was susceptible to mercury salts (Moore, I960) and resistant to tetracycline (Tc) by virtue of a plasmid that could be eliminated by growth at $44^{\circ}$ (May, Houghton \& Perret, 1964). The eliminated susceptible strain grew on nutrient agar containing $0.2 \mu \mathrm{g}$. Tc/ml.; on agar containing $0.4 \mu \mathrm{g}$. Tc/ml, colonies did not develop from an inoculum of $10^{8}$ staphylococci. With the uneliminated culture, identical colony counts were obtained on plain agar and on agar containing $4^{\circ} 0 \mu \mathrm{g}$. Tc/ml. At concentrations of up to $\mathrm{I} 60 \mu \mathrm{g}$. Tc/ml., some colonies developed but growth did not occur on nutrient agar containing $320 \mu \mathrm{g}$. Tc/ml. Three types of resistant cultures have been used: $(a)$ a culture transferred daily on plain nutrient agar; only 5 to $10 \%$ of the viable cocci from this culture produced colonies on agar containing $10 \mu \mathrm{g}$. Tc/ml.; (b) a highly resistant culture subcultured daily on nutrient agar containing $\mathrm{I} 60 \mu \mathrm{g}$. $\mathrm{Tc} / \mathrm{ml}$.; and (c) cultures with intermediate levels of resistance obtained by growth of type $(a)$ culture for a short period in nutrient broth containing tetracycline at different concentrations. 
Chemicals. Tetracycline hydrochloride was a gift from Lederle Laboratories, American Cyanamid Co., Pearl River, N.Y.; $\beta$-apo-5-oxy-tetracycline was from Chas. Pfizer \& Co., Groton, Conn., U.S.A.; chloramphenicol from Abic Ltd, Ramat Gan, Israel; nalidixic acid from Sterling-Winthrop Research Institute, Rensselaer, New York, U.S.A., through the courtesy of Dr Nachod; actinomycin D (Dactinomycin) was obtained from Merck Sharp \& Dohme, West Point, Pa, U.S.A.

Saline buffer was prepared as described by Sompolinsky, Ernst-Geller \& Segal (I967).

Culture media. Difco nutrient broth (NB) and nutrient agar (NA) were used. All cultures were incubated at $37^{\circ}, \mathrm{NB}$ cultures were grown in a water bath and aerated by shaking.

Viable counts were determined by plating appropriate dilutions of the bacterial suspension on NA; four replicate plates were prepared for each dilution and a total of IOO to 400 colonies were recorded on each plate.

Turbidity of bacterial cultures was determined with a Klett-Summerson photoelectrical colorimeter, using a red filter $(660 \mathrm{~nm}$.) for NB cultures. Five hundred Klett units $=$ extinction $(E)$ of $r \cdot 00$.

\section{RESULTS}

When an exponentially growing culture of Staphylococcus aureus I I I was inoculated into nutrient broth to give an initial turbidity of $0.032 \mathrm{E}$, growth continued at an exponential rate; addition of $10 \mu \mathrm{g}$. Tc/ml. caused a temporary decrease in the growth rate which then recovered to that of the antibiotic-free control. When $40 \mu \mathrm{g}$. Tc/ml. was added with the inoculum, no increase in turbidity occurred for $\mathrm{I} h$., after which growth occurred at a rate slightly less than that of the control (Fig. I). This type of growth curve in which the lag period varies with the drug concentration is seen when an inhibiting drug is inactivated by the culture (Sompolinsky \& Samra, 1968). However, no clear evidence for inactivation was found experimentally (Sompolinsky, Zaidenzaig, Ziegler-Schlomowitz \& Abramova, 1970).

Other possible explanations for this pattern of growth in $40 \mu \mathrm{g}$. Tc/ml. NB might be 'adaptation' to the drug during the lag period (Williams, 1967) or outgrowth of a few bacteria with initial resistance to $40 \mu \mathrm{g}$. Tc/ml. To examine these possibilities, further growth studies were performed by determining viable counts simultaneously on NA and on $40 \mu \mathrm{g}$. Tc/ml. NA (Fig. 2). The rate of growth demonstrated by counts on $40 \mu \mathrm{g}$. Tc/ml. NA soon approximated to that shown by viable counts on NA from cultures in NB and Io $\mu \mathrm{g}$. Tc/ml. NB. Furthermore, after 3 to $5 \mathrm{~h}$. the difference between the number of colony-forming units on NA and $40 \mu \mathrm{g}$. Tc/ml. NA was relatively constant, corresponding approximately to the original inoculum size $\left(3 \times 10^{7} \mathrm{cocci} / \mathrm{ml}\right.$.). These data might suggest that the population was initially heterogeneous in ability to grow on medium containing Tc, that only a few organisms $\left(4 \times 10^{6}\right.$ out of $\left.3 \times 10^{7}\right)$ were able to grow at $40 \mu \mathrm{g}$. Tc/ml. and that these eventually outnumbered the sensitive non-proliferating organisms.

However, selection from a heterogeneous bacterial population was not the only cause of development of tetracycline resistance. After growth in non-inhibitory concentrations of Tc $(0 \cdot \mathrm{I}$ or $\mathrm{I} \cdot 0 \mu \mathrm{g} . / \mathrm{ml}$ ), significant increase in the proportions of cocci growing on Io to $40 \mu \mathrm{g}$. Tc/ml. was observed (Table I). Resistance was also produced (Table 2 ) by growth with Io $\mu \mathrm{g}$. apo-oxy-tetracycline/ml. which is virtually noninhibitory. In these experiments, practically the whole bacterial population increased 
in resistance through contact with Tc. The apparent discrepancy between these and earlier results could be explained by the assumption that resistance depends on the synthesis of a specific protein which is induced by Tc at a rate dependent on the concentration of antibiotic. Apo-oxy-tetracycline would, according to the results in Table 2, be a less effective inducer. Development of resistance was inhibited by chloramphenicol as would be expected for such induction.

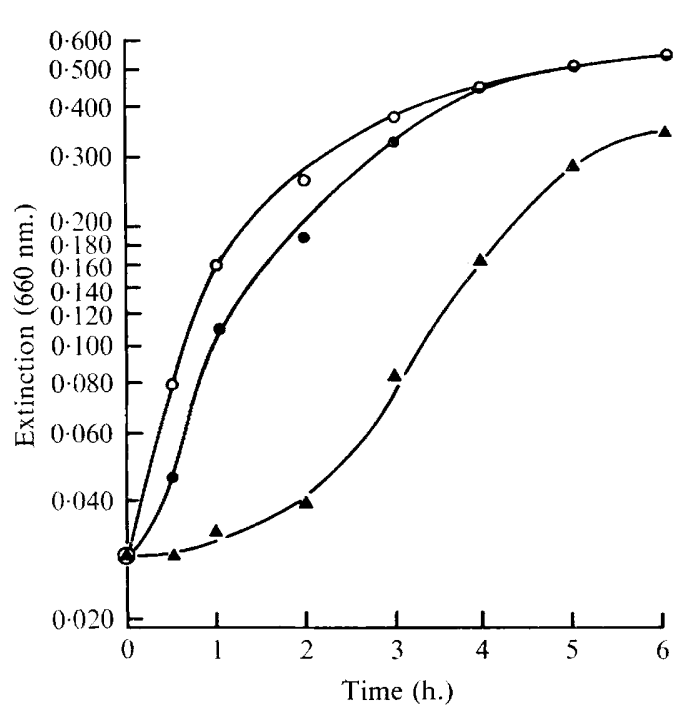

Fig. I

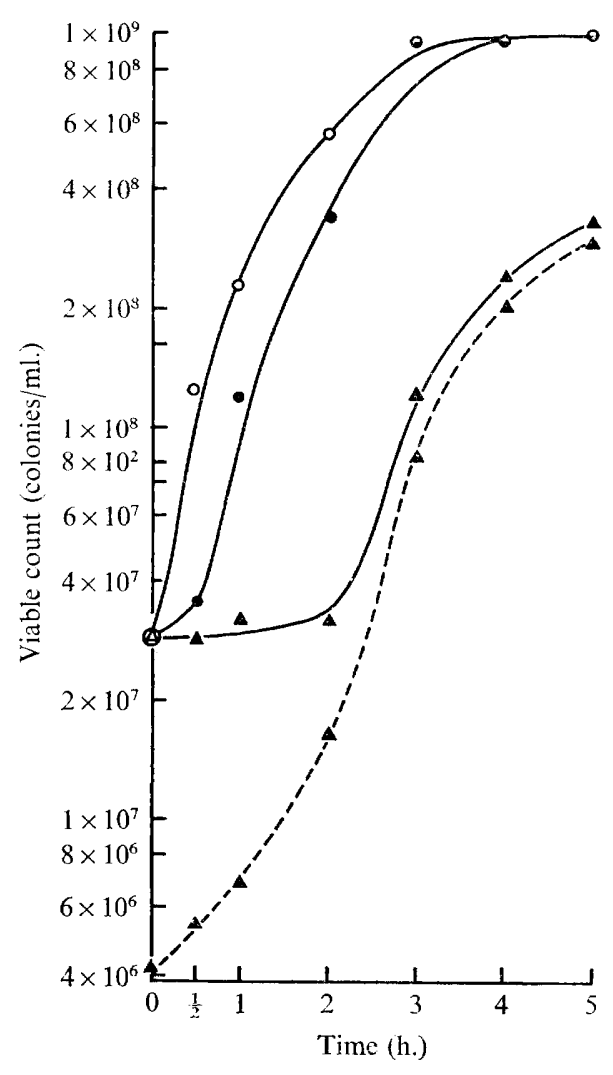

Fig. 2

Fig. I. Growth of Staphylococcus aureus I I I in nutrient broth $(\mathrm{NB})(\mathrm{O}-\mathrm{O})$; tetracycline (Tc) $10 \mu \mathrm{g} . / \mathrm{ml}$. NB $(-)$; and $40 \mu \mathrm{g}$. Tc/ml. NB (A-A). Determined by measurement of extinction $(E)$ at $660 \mathrm{~nm}$.

Fig. 2. Growth of Staphylococcus aureus I I in nutrient broth $(\mathrm{NB})(\mathrm{O}-\mathrm{O})$; io $\mu \mathrm{g}$. tetracycline (Tc) $/ \mathrm{ml}$. NB $(-)$ ); and $40 \mu \mathrm{g}$. Tc/ml. NB. $(\boldsymbol{\Delta}-\mathbf{A})$. Determined by viable counts on nutrient agar (NA). The culture in $40 \mu \mathrm{g}$. Tc/ml. NB was also counted on $40 \mu \mathrm{g}$. Tc/ml. NA. (A- - - A).

When an inhibitor of protein synthesis is also an inducer, no simple kinetics of induction can be expected (Shaw \& Brodsky, 1968). Figure $3 a$ shows that growth of Staphylococcus aureus I I in NB + Tc was independent of the drug concentration in the range 5 to Io $\mu \mathrm{g}$. $/ \mathrm{ml}$. and that growth after $4 \mathrm{~h}$. was little influenced by $20 \mu \mathrm{g} . / \mathrm{ml}$., but considerably by $40 \mu \mathrm{g}$. $/ \mathrm{ml}$. If $\mathrm{Tc}$ is an inducer and induction is concentrationdependent, it would be expected that the highest concentration of the drug with no 
Table I. Increase in phenotypical resistance to tetracycline in Staphylococcus aureus III during growth in nutrient broth with subinhibitory concentrations of the drug

\begin{tabular}{|c|c|c|c|c|c|c|c|}
\hline \multirow{3}{*}{$\begin{array}{l}\text { Time } \\
\text { (h.) }\end{array}$} & \multicolumn{5}{|c|}{ Growth in Tc-free NB } & & \\
\hline & \multirow[t]{2}{*}{$\begin{array}{l}\text { Viable } \\
\text { cocci on } \\
\text { plain NA }\end{array}$} & \multicolumn{4}{|c|}{$\begin{array}{l}\text { Cocci resistant to } \\
(\mu \mathrm{g} . \mathrm{Tc} / \mathrm{ml} .)\end{array}$} & & \\
\hline & & 5 & IO & 20 & 40 & & \\
\hline 0 & $2.0 \times 10^{7}$ & $84 \cdot 7^{*}$ & $79 \cdot 2$ & $3 \cdot I$ & nt & & \\
\hline 2 & $9.5 \times 10^{7}$ & $66 \cdot 5$ & $25 \cdot I$ & 0 & nt & & \\
\hline 4 & $3.3 \times 10^{8}$ & $58 \cdot 5$ & $9 \cdot 9$ & 0 & nt & & \\
\hline \multirow{3}{*}{$\begin{array}{l}\text { Time } \\
\text { (h.) }\end{array}$} & \multicolumn{7}{|c|}{ Growth in $0 . \mathrm{I} \mu \mathrm{g} . \mathrm{Tc} / \mathrm{ml}$. NB } \\
\hline & \multirow{2}{*}{$\begin{array}{c}\text { Viable } \\
\text { cocci on } \\
\text { plain NA }\end{array}$} & \multicolumn{6}{|c|}{$\begin{array}{l}\text { Cocci resistant to } \\
(\mu \mathrm{g} . \mathrm{Tc} / \mathrm{ml} .)\end{array}$} \\
\hline & & 5 & 10 & 20 & 40 & 80 & $160^{\prime}$ \\
\hline 0 & $2.0 \times 10^{7}$ & $84 \cdot 7$ & $79 \cdot 2$ & $3 \cdot \mathrm{I}$ & nt & $\mathrm{nt}$ & nt \\
\hline 2 & $9.6 \times 10^{7}$ & $88 \cdot 2$ & $77 \cdot 8$ & 12.9 & 0.9 & 0 & 0 \\
\hline 4 & $3.1 \times 10^{8}$ & $104 \cdot 8$ & $99 \cdot 2$ & $21 \cdot 0$ & 0 & o & 0 \\
\hline
\end{tabular}

\begin{tabular}{|c|c|c|c|c|c|c|c|}
\hline \multirow{3}{*}{$\begin{array}{l}\text { Time } \\
\text { (h.) }\end{array}$} & \multicolumn{7}{|c|}{ Growth in $\mathrm{I} \cdot 0 \mu \mathrm{g} . \mathrm{Tc} / \mathrm{ml}$. NB } \\
\hline & \multirow{2}{*}{$\begin{array}{l}\text { Viable } \\
\text { cocci on } \\
\text { plain NA }\end{array}$} & \multicolumn{6}{|c|}{$\begin{array}{l}\text { Cocci resistant to } \\
(\mu \mathrm{g} . \mathrm{Tc} / \mathrm{ml} .)\end{array}$} \\
\hline & & 5 & 10 & 20 & 40 & 80 & 160 \\
\hline 0 & $2.0 \times 10^{7}$ & $84 \cdot 7$ & $79 \cdot 2$ & $3 \cdot I$ & $\mathrm{nt}$ & nt & nt \\
\hline 2 & $9.2 \times 10^{7}$ & 89.0 & $80 \cdot 8$ & $58 \cdot 3$ & $9 \cdot 2$ & $I \cdot 6$ & 0 \\
\hline 4 & $2.9 \times 10^{8}$ & $99 \cdot 6$ & IOI'2 & 100.0 & $24 \cdot 6$ & 10.6 & 0 \\
\hline
\end{tabular}

Abbreviations: $\mathrm{NA}=$ nutrient agar; $\mathrm{NB}=$ nutrient broth; $\mathrm{Tc}=$ tetracycline; $\mathrm{nt}=$ not tested.

* Resistant cocci, determined by viable count on NA + indicated concentrations of Tc, expressed as $\%$ of viable count on NA.

Table 2. Influence of pre-incubation with tetracycline or apo-oxy-tetracycline on resistance of Staphylococcus aureus III to tetracycline

\begin{tabular}{lcccc} 
& \multicolumn{3}{c}{ Cocci resistant to tetracycline $(\mu \mathrm{g} . / \mathrm{ml})}$. \\
Pre-incubation conditions (3 h.) & 20 & 40 & 80 & $\mathrm{I} 60$ \\
No Tc & $33 \cdot 4^{*}$ & 0 & $\mathrm{nt}$ & $\mathrm{nt}$ \\
Tc ro $\mu \mathrm{g} . / \mathrm{ml}$. NB & $99 \cdot 6$ & $79 \cdot 0$ & $66 \cdot 8$ & $56 \cdot 8$ \\
apo-oxy-Tc 10 $\mu \mathrm{g} . / \mathrm{ml}$. NB & $65 \cdot 8$ & $32 \cdot 3$ & $4 \cdot 9$ & $\mathrm{o}$ \\
Tc ro $\mu \mathrm{g} . / \mathrm{ml} .+$ chloramphenicol & $6 \cdot 7$ & 0 & 0 & 0
\end{tabular}

Abbreviations: $\mathrm{Tc}=$ tetracycline; $\mathrm{NB}=$ nutrient broth; $\mathrm{nt}=$ not tested.

* Resistant cocci, determined by viable count on NA+ indicated concentrations of Tc, expressed as $\%$ of viable count on NA.

significant inhibitory effect would be most rapidly effective in induction. This was confirmed by the experiments reported in Fig. $3 b$.

In a similar experiment, the appearance of cocci resistant to $160 \mu \mathrm{g}$. $\mathrm{Tc} / \mathrm{ml}$. during growth in $20 \mu \mathrm{g}$. Tc/ml. NB was depicted at shorter time intervals (Fig. 4); at the time of positive growth acceleration there was a rapid increase in the proportion of highly 
resistant bacteria from 8 to $60 \%$ of the whole population. Development of phenotypical high-level resistance seemed therefore to be associated with other vital metabolic activities of the organisms. Further experiments (Tables 2, 3; Fig. $5 a$ to $c$ ) indicated that protein synthesis was involved, since no highly resistant cocci developed in the presence of chloramphenicol, and substitution of NB by saline buffer caused a striking delay in the appearance of high-level resistance. This is in accordance with the observation that inhibitory concentrations of Tc inhibit induction (Fig. I).
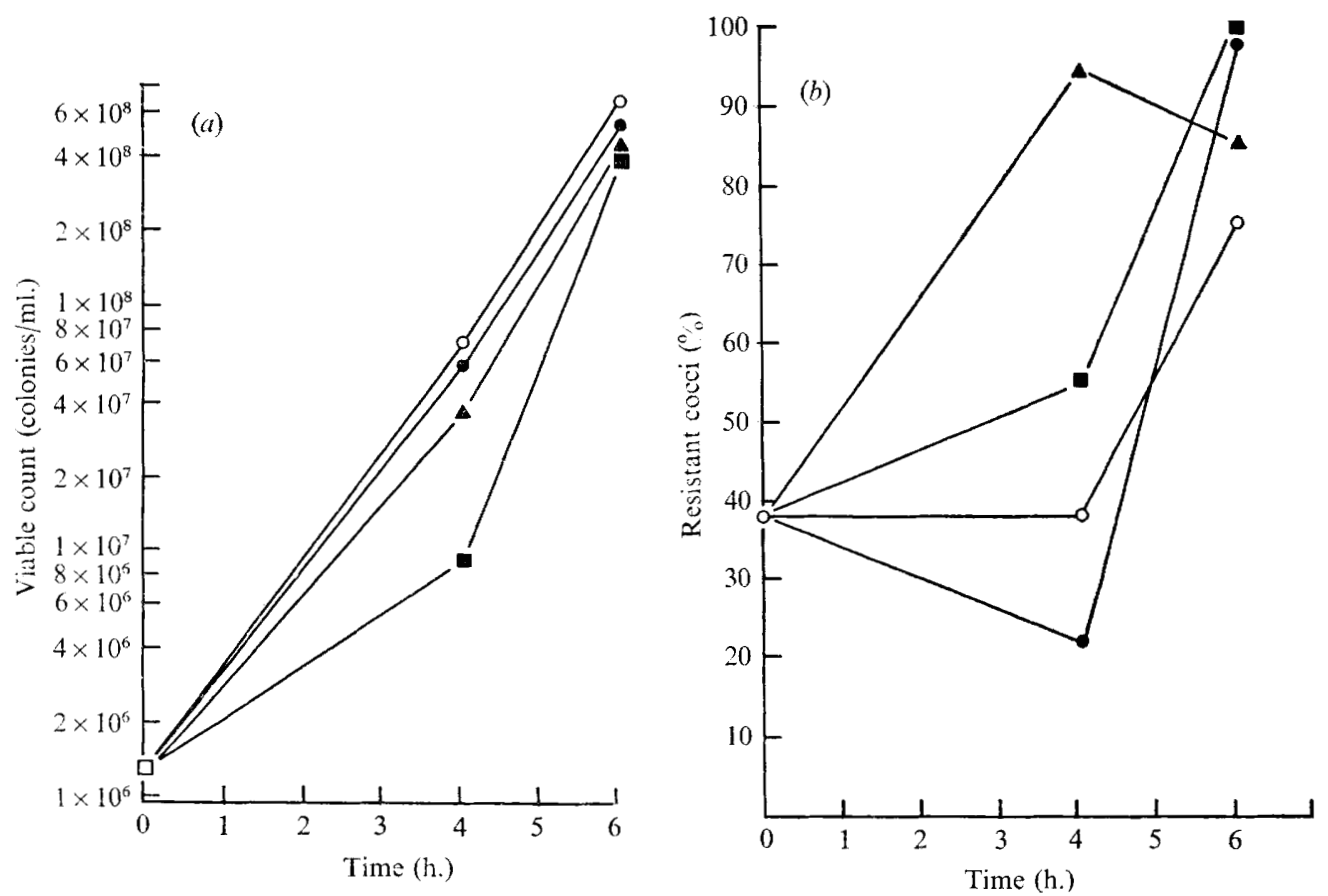

Fig. $3 a$. Growth of Staphylococcus aureus $11 \mathrm{I}$ in nutrient broth (NB) with $5 \mu \mathrm{g}$. tetracycline (Tc) $/ \mathrm{ml}$. (O-O); Io $\mu \mathrm{g}$. Tc/ml. NB $(-\mathbf{O}) ; 20 \mu \mathrm{g}$. Tc/ml. NB $(\mathbf{\Delta - \Delta}) ;$ and $40 \mu \mathrm{g}$. Tc/ $\mathrm{ml}$. NB ( - $\mathbf{-})$. Determined by viable counts on nutrient agar (NA).

Fig. $3 b$. Change in frequency of bacteria resistant to $160 \mu \mathrm{g}$. Tc/ml. in the cultures of Fig. $3 a$. Determined by viable counts on $160 \mu \mathrm{g}$. Tc/ml. NA and calculated as \% of viable count on NA.

In a Tc-susceptible (eliminated) culture of Staphylococcus aureus III, growth in $0.05 \mu \mathrm{g}$. Tc/ml. NB had no influence on resistance; the strain remained resistant to $0.2 \mu \mathrm{g}$. Tc/ml. and susceptible to $0.4 \mu \mathrm{g}$. Tc/ml.

The increased resistance of the non-eliminated cultures achieved by incubation with subinhibitory concentrations of Tc might be due either to induction of resistance through derepression of the synthesis of a specific 'resistance protein' or to the development of a higher multiplicity of 'resistance genes' (plasmids) per coccus. In the latter case, induction of increased resistance would require DNA synthesis, and therefore be susceptible to nalidixic acid, whereas induction by repressor inactivation would be susceptible only to drugs that inhibit transcription (actinomycin D) or translation (chloramphenicol) of the resistance gene. In experiments with nalidixic acid at $200 \mu \mathrm{g}$./ml., significant increase in viable count of a culture of Staphylococcus aureus I I I 


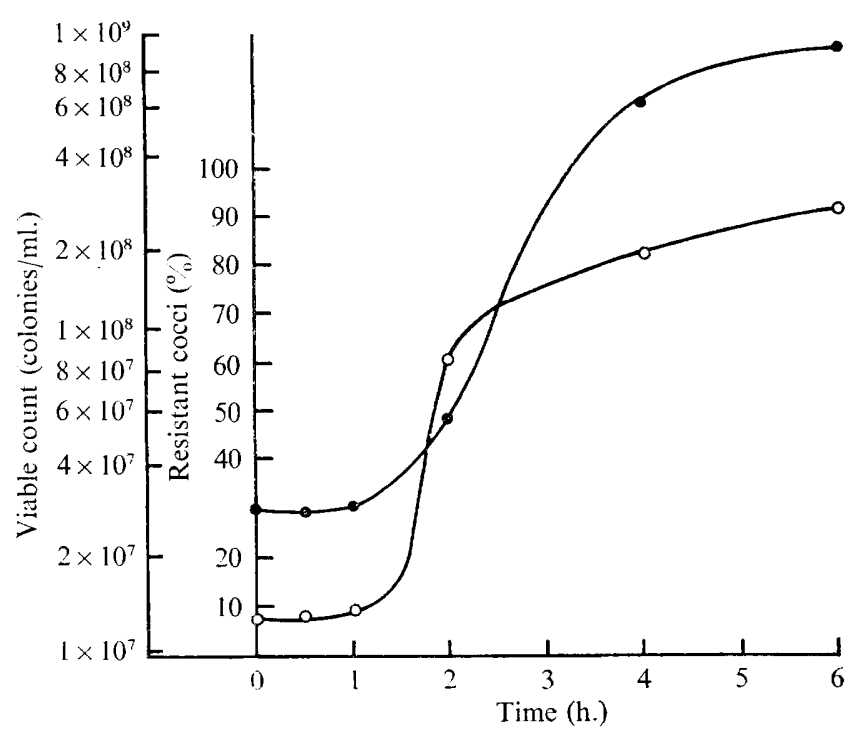

Fig. 4. Kinetics of increase in resistance of Staphylococcus aureus I I I, growing in nutrient broth (NB) containing $20 \mu \mathrm{g}$. tetracycline (Tc)/ml. Growth curve of broth cultures by viable counts on nutrient agar (NA) (-), and \% resistant cocci by viable count on $\mathrm{I} 60 \mu \mathrm{g}$. Tc/ml. $\mathrm{NA}$ as percentage of viable count on NA. $(\mathrm{O}-\mathrm{O})$.
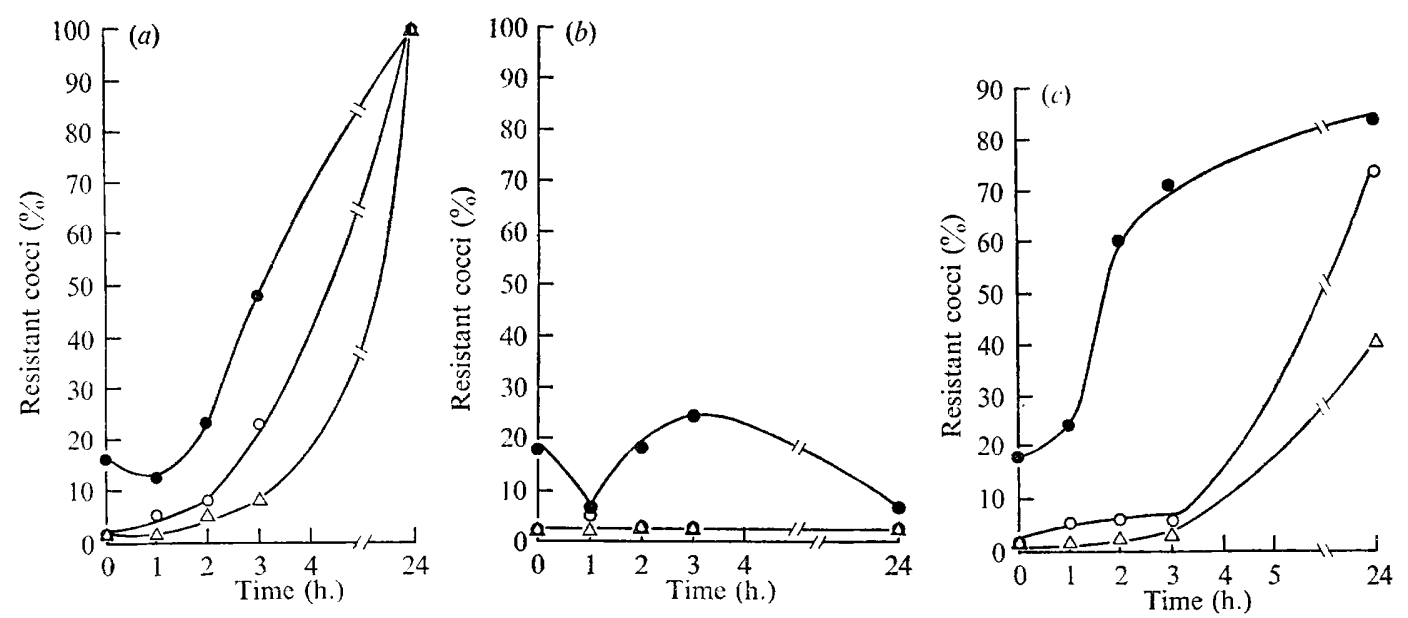

Fig. 5. Frequency of colony-forming staphylococci (Staphylococcus aureus I I I) from nutrient broth (NB) culture, developing on $20 \mu \mathrm{g}$. tetracycline (Tc) $/ \mathrm{ml}$. nutrient agar (NA) $40 \mu \mathrm{g}$. Tc/ml. NA $(\mathrm{O}-\mathrm{O})$; and $80 \mu \mathrm{g}$.Tc $/ \mathrm{ml}$. NA $(\Delta-\Delta)$; as percentage of viable count on NA. Cultures incubated during the time indicated, in $(a) 20 \mu \mathrm{g}$. Tc/ml. NB, (b) $20 \mu \mathrm{g}$. Tc/ $\mathrm{ml}$. NB $+200 \mu \mathrm{g}$. chloramphenicol $/ \mathrm{ml}$., (c) $20 \mu \mathrm{g}$.Tc $/ \mathrm{ml}$. saline buffer. Inoculum size was in all cases $\mathrm{I} .6 \times 10^{7}$ bacteria $/ \mathrm{ml}$. After $24 \mathrm{~h}$, viable counts on plain NA were $(a) 3.9 \times 10^{8} / \mathrm{ml}$., (b) $2.3 \times 10^{6} / \mathrm{ml}$. and $(c) 3.2 \times 10^{5} / \mathrm{ml}$. The bacteria incubated with chloramphenicol were washed twice in saline buffer before plating. 
during $2 \mathrm{~h}$. incubation, was prevented, whereas $256 \mu \mathrm{g} . / \mathrm{ml}$. caused an extensive decrease in the number of colony-forming units. Table 3 shows that $\mathrm{I} \cdot 0 \mu \mathrm{g}$. Tc/ml. caused a rapid increase in resistance of a previously entirely uninduced culture, in

Table 3. Induction of tetracycline resistance in Staphylococcus aureus III in presence of nalidixic acid

An exponential-phase culture of $S$. aureus II , in nutrient broth (NB) (O.D. $=0.100)$, was diluted in NB + nalidixic acid to a calculated o.D. of 0.008 ; the other indicated drugs were added and the cultures incubated with aeration. Samples of the cultures were centrifuged, the organisms washed once in saline buffer, suspended and diluted in saline buffer and viable counts determined on NA and NA+Tc.

Drugs in incubation medium (in $\mu \mathrm{g} . / \mathrm{ml}$.)

Nil

Nalidixic acid 200.0

Nalidixic acid 200.0

+ tetracycline 20.0

Nalidixic acid $200 \cdot 0$

+ tetracycline 5.0

Nalidixic acid $200 \cdot 0$

+ tetracycline $r \cdot O$

Nalidixic acid $200 \cdot 0$

+ tetracycline 0.1

Nalidixic acid $200 \cdot 0$
+ chloramphenicol $200 \cdot 0$
+ tetracycline $\mathrm{I} \cdot \mathrm{O}$$\quad\left\{\begin{array}{l}\mathrm{I} \\ 2\end{array}\right.$

Nalidixic acid 200.0

+ actinomycin D I.5

+ tetracycline $I \cdot O$

Cocci resistant to tetracycline $(\mu \mathrm{g} . / \mathrm{ml}$.)

\begin{tabular}{|c|c|c|c|}
\hline 10 & 20 & 40 & 80 \\
\hline $16 \cdot 2 *$ & 0.9 & $<0.01$ & $<0.01$ \\
\hline $7 \cdot 8$ & 0.3 & $<0.01$ & $<0.01$ \\
\hline $9 \cdot 2$ & 0.3 & $<0.0 \mathrm{I}$ & $<0.01$ \\
\hline nt & 0.4 & 0.02 & $<0.01$ \\
\hline $12 \cdot 9$ & 0.01 & $<0.0$ I & $<0.01$ \\
\hline $\mathrm{nt}$ & 0.01 & $<0.01$ & $<0.01$ \\
\hline $12 \cdot 4$ & $0 \cdot 2$ & $<0.0$ I & $<0.01$ \\
\hline $22 \cdot 5$ & $2 \cdot 8$ & 0.7 & 0.2 \\
\hline $106 \cdot 8$ & $60 \cdot 2$ & $5 \cdot 7$ & $<0.01$ \\
\hline $9 \mathrm{I} \cdot \mathrm{O}$ & $60 \cdot 3$ & $22 \cdot 9$ & $I \cdot 6$ \\
\hline $92 \cdot 3$ & $68 \cdot 6$ & $28 \cdot 6$ & $I \cdot 5$ \\
\hline $85 \cdot 6$ & $23 \cdot 6$ & $7 \cdot 0$ & 0.6 \\
\hline $17 \cdot 3$ & $I \cdot I$ & $<0.0 \mathrm{I}$ & $<0.0 \mathrm{r}$ \\
\hline 12.4 & $2 \cdot 2$ & 0.02 & $<0.01$ \\
\hline 13.5 & $7 \cdot 6$ & 0.5 & 0.07 \\
\hline $7 \cdot 8$ & $3 \cdot 0$ & 0.3 & 0.12 \\
\hline
\end{tabular}

$\mathrm{nt}=\mathbf{\text { Not tested. }}$

* Resistant cocci, determined by viable count on NA+indicated concentrations of Tc, expressed as $\%$ of viable count on NA.

Table 4. Loss of phenotypical high-level resistance to tetracycline after growth on drug-free nutrient agar

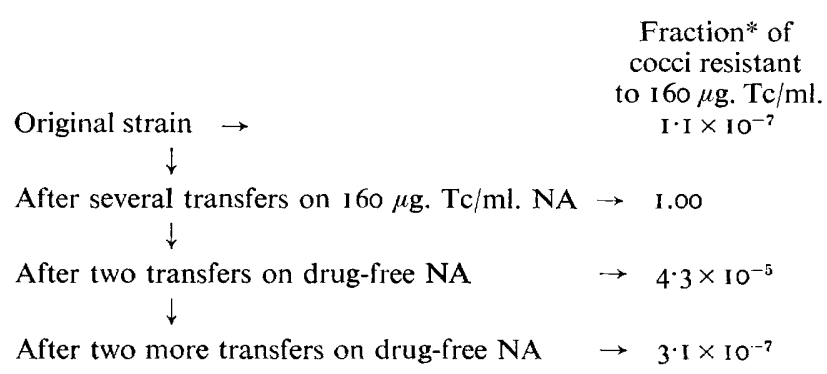

Abbreviations: $\mathrm{Tc}=$ tetracycline; NA $=$ nutrient agar.

* Determined by colony counts on plain agar and on nutrient agar containing $160 \mu \mathrm{g}$. Tc/ml. NA. 
spite of the addition of nalidixic acid. Chloramphenicol and actinomycin D, added to nalidixic acid $+\mathrm{Tc}$, strongly inhibited induction of increased resistance. In these experiments, $20 \mu \mathrm{g}$. Tc/ml. inhibited induction almost entirely, while $5^{\circ} 0$ and $0.1 \mu \mathrm{g}$. $\mathrm{Tc} / \mathrm{ml}$. were less effective than $\mathrm{I} \cdot 0 \mathrm{~g}$. Tc/ml.

When Staphylococcus aureus I I was grown in NB + Tc until the whole population was phenotypically of high-level resistance, and the bacteria were subcultured on plain NB or NA, high-level resistance was gradually lost. Table 4 shows that after four subcultures the frequency of high-level resistant cocci was as in a culture that has had no previous contact with the drug. If high resistance depends on induction of synthesis of a specific protein, then return to lower levels of resistance would be explicable simply as dilution of this protein by cell division and re-repression of its synthesis de novo.

\section{DISCUSSION}

Resistance of staphylococci to penicillin (Richmond, 1965) and chloramphenicol (Shaw \& Brodsky, 1968) is due to inactivation of the drugs by enzymes synthesized after induction, the respective drugs serving as inducers. Our results indicate that in Tc resistance, although resistance is probably not due to inactivation, an inducible genetic system is involved. This has not been shown for low-level resistance; either the coccus produces constitutively a small amount of the resistance protein, or it has sufficient time to produce such small amounts, protecting against low concentrations of Tc, before uptake inhibits further protein synthesis. High resistance of a bacterial population, however, depended under our experimental conditions on pre-incubation with subinhibitory concentrations of the drug. This induction of high resistance was inhibited by both chloramphenicol and actinomycin $D$, but was not dependent on growth since it occurred in cultures inhibited by nalidixic acid during the period of contact with tetracycline.

It may seem curious that an inhibitor of protein synthesis is also an inducer for the development of resistance by a procedure that depends on protein synthesis. Preincubation with low concentration of the drug in order to induce high-level resistance is probably an entirely artificial laboratory procedure with no biological importance. However, it is possible that in the natural environment of the staphylococcus Tc molecules might penetrate even more slowly than in laboratory media, due to differences in the metabolic state of the organism; under such conditions the organism might be induced to develop a high level of resistance before phenotypical expression is inhibited by the inducer itself.

The authors are indebted to Miss Herna de Vries for skilful assistance, and to Dr E. Goldschmidt (Neopharm Ltd), Mr Keizman (Abic Ltd) and Mr Nissan Preminger for kind assistance in obtaining the drugs used. A part of this study was supported by research grant 64/3/32 from Bar Ilan University.

\section{REFERENCES}

May, J. W., Houghton, R. H. \& Perret, C. J. (1964). The effect of growth at elevated temperature on some heritable properties of Staphylococcus aureus. Journal of General Microbiology 37, I 57-169.

Moore, B. (1960). A new screen test and selective medium for the rapid detection of epidemic strains of Staph. aureus. Lancet ii, 453-458.

Richmond, M. H. (1965). Dominance of the inducible state in strains of Staphylococcus aureus containing two distinct penicillinase plasmids. Journal of Bacteriology 9o, 370-374. 
Shaw, W. V. \& Brodsky, R. F. (1968). Characterization of chloramphenicol acetyltransferase from chloramphenicol-resistant Staphylococcus aureus. Journal of Bacteriology 95, 28-36.

Sompolinsky, D., Ernst-Geller, Z. \& Segal, S. (1967). Metabolic disorders in thiamineless dwarf strains of Staphylococcus aureus. Journal of General Microbiology 48, 205-213.

Sompolinsky, D. \& SAMrA, Z. (1968). Mechanism of high-level resistance to chloramphenicol in different Escherichia coli variants. Journal of General Microbiology 5o, 55-66.

Sompolinsky, D., Yiflah, Y. \& ABoud, M. (1968). The mechanism of ultraviolet induction in lysogenic Staphylococcus aureus. Journal of General Virology 2, 347-356.

Sompolinsky, D., Zaidenzaig, Y., Ziegler-Schlomowitz, R. \& Abramova, N. (I970). Mechanism of tetracycline resistance in Staphylococcus aureus. Journal of General Microbiology 62, 351-362.

Williams, R. F. (1967). Mercury resistance and tetracycline resistance in Staphylococcus aureus. Journal of Hygiene 65, 299-309. 